\title{
Fish Catch Is Related to the Fluctuations of a Western Boundary Current
}

\author{
LIE-YAUW OEY \\ National Central University, Jhongli City, Taiwan, and Princeton University, Princeton, New Jersey \\ JIA WANG \\ Jimei University, Xiamen, China \\ M.-A. LEE \\ Center of Excellence for Ocean Engineering, National Taiwan Ocean University
}

(Manuscript received 7 March 2017, in final form 8 January 2018)

\begin{abstract}
In eastern boundary upwelling ecosystems, substantial variance of biological productivity $(\sim 50 \%)$ can often be related to physical forcing such as winds and ocean temperatures. Robust biophysical connections are less clear-cut in western boundary currents. Here the authors show that interannual variation of fish catch along the western boundary current of the North Pacific, the Kuroshio, significantly correlates $(r=0.67$; $p<0.001$ ) with the current's off-slope (more fish) and on-slope (less fish) sideways shifts in the southern East China Sea. Remotely, transport fluctuations and fish catch are related to the oscillation of a wind stress-curl dipole in the tropical-subtropical gyre of the western North Pacific. Locally, the current's sideways fluctuations are driven by transport fluctuations through a feedback process between along-isobath pressure gradients and vertical motions: upwelling (downwelling) during the off-slope (on slope) shift, which in turn significantly enhances (depresses) the chlorophyll-a (Chl-a) concentration in winter and early spring. The authors hypothesize that changes in the phytoplankton biomass as indicated by the Chl-a lead to changes in copepodites, the main food source of the fish larvae, and hence also to the observed variation in fish catch.
\end{abstract}

\section{Introduction}

Upwelling regions constitute about $1 \%$ of the world's ocean surface but account for over $50 \%$ of the fish catch (FC) worldwide (Blanchette et al. 2009). Upwelling brings nutrients to the euphotic zone; through photosynthesis it supports phytoplankton growth and sustains marine food web within a relatively small area that makes the upwelling region highly productive in harvestable fish (Lalli and Parsons 1997; Cury et al. 2000; Barber 2001; Egerton 2007). Besides the wind-driven upwelling regions next to the eastern boundaries of the world's oceans and near the equator (Tomczak 1981; Huyer 1983; Hill et al. 1998; Kessler 2006), upwelling also occurs along western boundary currents (Lee and

Supplemental information related to this paper is available at the Journals Online website: https://doi.org/10.1175/JPO-D-17-0041.s1.

Corresponding author: Leo Oey, lyo@alumni.princeton.edu
Atkinson 1983; Oey et al. 1987, 1992, 2010; Glenn and Ebbesmeyer 1994; Ito et al. 1995; Yanagi et al. 1998; Ichikawa and Beardsley 2002; Isobe 2004, 2008; Chang et al. 2009, 2010). Extensive studies have shown that the inshore edge of the Kuroshio in the southern East China Sea (ECS; Fig. 1a) is a favorite ground for mackerel to congregate and breed (Asami 1974; Sassa and Konishi 2002; Sassa et al. 2006, 2008, 2014, 2016; Kim et al. 2007; Kanaji et al. 2009; Yukami et al. 2009; Sassa and Tsukamoto 2010; Lu et al. 2013; Chen et al. 2014; Li et al. 2014a,b; Yasuda et al. 2014). It is also well known by local fishermen as being one of the most productive fishing sites in the region. Northeast of Taiwan in an area of less than $3 \%$ of the ECS, annual mackerel catch amounts to approximately $7 \%$ of the total catch for the entire sea (Yoda et al. 2012; Lu et al. 2013). Here, the Kuroshio turns abruptly eastward following the continental slope,

Publisher's Note: This article was revised on 19 June 2018 to correct the affiliation of coauthor M.-A. Lee. 

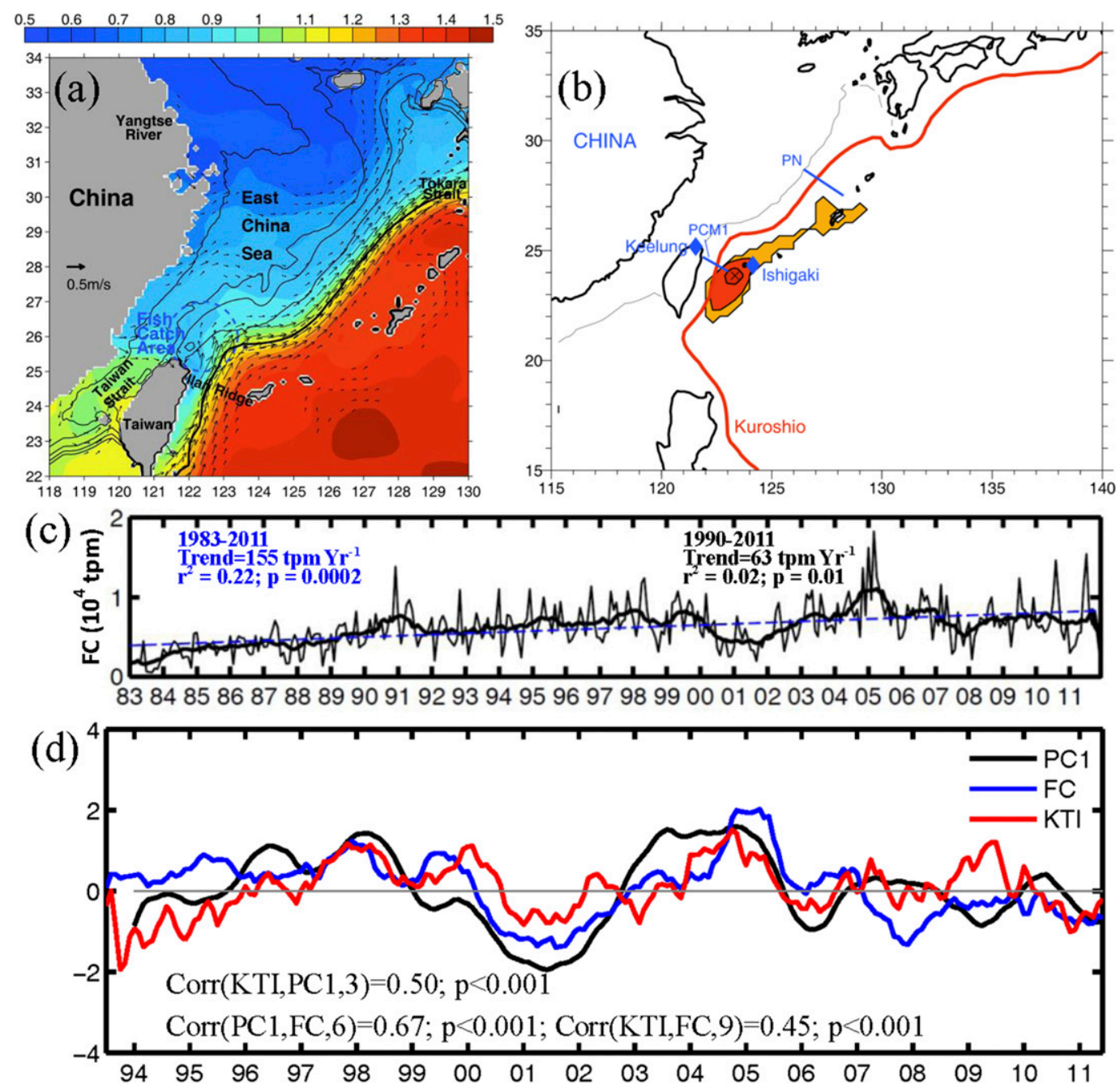

FIG. 1. (a) Mean absolute dynamic topography ( $\mathrm{m}$; shading) and geostrophic velocity ( $\mathrm{m} \mathrm{s}^{-1}$ ) from AVISO (Wang and Oey 2016). Thin contours are isobaths: 50, ., $200 \mathrm{~m}$. (b) Correlation of measured Kuroshio transport (Johns et al. 2001) with $\eta_{\mathrm{AVI}}$ : shading and contours $=0.4,0.6$, and 0.8 indicate where $p \leq 0.05 ; \times$ shows location of maximum correlation $(=0.9)$ where KTI is defined. Red line shows mean Kuroshio path. Thin contour is 200-m isobath. (c) Monthly FC [tons per month (tpm)] with trend; thick line shows 24-month running mean. Legends show trends, $r^{2}$, and $p$ values for the indicated periods. (d) Time series of PC1, FC, and KTI (normalized and long-term trends removed); the PC1 and KTI are shifted to the right by 6 and 9 months, respectively. Legends show maximum lagged correlations $\operatorname{Corr}(\mathrm{A}, \mathrm{B}$, month) of series $\mathrm{A}$ and $\mathrm{B}$, and months where A leads $\mathrm{B} ; p$ is the $p$ value.

producing strong sideway fluctuations (Wang and Oey 2014, 2016) and vigorous cross-slope exchanges of water mass and vertical motion that modulate the nutrient concentration of the shelf (Liu et al. 1992a,b; Wong et al. 2004; Chen and Wang 2006; Chang et al. 2010). Wang and Oey (2014) found that Kuroshio transport is closely related to the sideway fluctuation of the Kuroshio about its mean path. The sideways fluctuation is characterized by the path's EOF mode 1, which accounts for $44 \%$ of the total variance. The corresponding principal component (PC1) is here taken as the Kuroshio sideways fluctuation index. The Kuroshio shifts offshore
$(\mathrm{PC} 1>0)$ as transport increases and onshore $(\mathrm{PC} 1<0)$ when transport decreases. We will (below) demonstrate that as Kuroshio transport increases, isotherms steepen and are uplifted inshore of the current, and the Kuroshio front moves offshore. Uplifted isotherms bring nutrientrich subsurface waters to the surface, which may favor phytoplankton blooming (Sverdrup 1953; Franks 1992). Since phytoplankton correlates well with copepodites, the foods for mackerel larvae and juveniles (Sassa et al. 2014), phytoplankton abundance may in turn favor more FC. While it may be difficult to associate short-term (daily-monthly) biomass variability to 
circulation physics, it is plausible that low-frequency, interannual fluctuations in the Kuroshio can modulate phytoplankton production, mackerel breeding variability, and perhaps also fish catches. The problem has not been previously explored. In this study, we show that an intensified (weakened) Kuroshio transport (KT) shifts the current off slope (on slope), producing upwelling (downwelling) that spurs (suppresses) phytoplankton growth. We use long-term satellite altimeter (22 yr), ocean color $(18 \mathrm{yr})$, and fish catch $(22 \mathrm{yr})$ data. We show that the sideways fluctuations of the Kuroshio are significantly correlated with phytoplankton and fish catch: higher (lower) phytoplankton and more (less) fish when the current is off slope (on slope). We use observation and model to explain the physical causes.

\section{Mackerel in the East China Sea-A brief review}

Fishery dynamics depend in a complex way on the animal's physiology that responds nonlinearly to the biophysical environments. A complete study would require a comprehensive set of biophysical observations as well as ecosystem model experiments, which is beyond the scope of this study. Nonetheless, in order to understand how physical parameters may explain the fish catch data, it is necessary to have some knowledge of the fish habitat. A brief review is given here.

Of the fish in the fish catch data (see the section $2 \mathrm{a}$ below) ninety-nine percent is of the mackerel species, including jack mackerel (Trachurus japonicus), chub mackerel (Scomber japonicus), and spotted mackerel (Scomber australasicus) (Yukami et al. 2009; Takahashi et al. 2014; Lu et al. 2013); our focus will be on mackerel. Mackerel spawn through external fertilization; sperm and eggs are released near the surface from winter to early spring [January, February, and March (JFM)] over the southern ECS shelf break and outer shelf northeast of Taiwan, roughly between the 75- to 200-m isobaths (Yukami et al. 2009; Sassa and Tsukamoto 2010; Sassa et al. 2014); for brevity this region is referred to as the fish catch area (Fig. 1a). Here, the seawater is kept warm [sea surface temperature $(\mathrm{SST}) \approx 15^{\circ}-23^{\circ} \mathrm{C}$ ] and brackish (salinity $S \approx 33.5-35 \mathrm{psu}$ ) by frequent intrusions of warm and saline Kuroshio water that mixes with the cold and less-saline coastal water (Oey et al. 2013; Wang and Oey 2014, 2016). As the growth rate of fish is closely related to the habitat temperature, which affects the larval metabolic rate (Houde 1989; Houde and Zastrow 1993; Sanchez-Ramirez and Flores-Coto 1998; Shoji et al. 2006), the warmer the temperature is the more rapid is the fish growth (Sassa et al. 2014). However, the ideal temperatures for vigorous growths (assuming adequate food) should be neither too cold nor too warm, within what we referred to as the "Goldilocks temperature range" of approximately $18^{\circ}$ to $23^{\circ} \mathrm{C}$ depending on the particular species (Sassa and Tsukamoto 2010; Sassa et al. 2014).

Mackerel larvae and juveniles feed on zooplankton and copepodites such as the Paracalanus spp. and Oncaea spp. near the surface in winter, which in turn consume phytoplankton (Chen et al. 2014; Sassa et al. 2014). There is a significant correlation between chlorophyll (Chl-a) and copepodites such that high Chl-a generally indicates also high food availability for the young fish (Sassa et al. 2014), and vice versa. Larvae and juveniles take 1-3 months (i.e., from spring to summer) to grow into adults, when the fish then migrate into deeper, cooler subsurface layers of the ocean, presumably to seek shelter from the summer heat near the surface. Adult mackerel hunt small crustaceans, shrimp, and squid, as well as smaller fish such as herrings and sardines, and can live up to 10 or more years. However, while the fish catch data reflects adult fish, studies show that recruitment of fish [number of new young fish that enter a population in a given year (Houde 1987; Sassa et al. 2014)] is largely determined during their early life stages, when the larvae and juveniles are vulnerable to a variety of physical and biological factors that affect their survival (Houde 1987; Sassa and Tsukamoto 2010; Sassa et al. 2014, 2016). Faster-growing larvae and juveniles have a higher probability of survival than slowergrowing individuals. Therefore, more favorable winter conditions in terms of temperature and food availability lead to greater survival, yielding larger recruitment and fish catch (Pope et al. 2010; Sassa et al. 2014).

\section{Data and methods}

\section{a. Fish catch data}

Monthly FC data northeast of Taiwan from 1983 to 2011 (Fig. 1a) were obtained from the fisheries reports of the Council of Agriculture of Taiwan (CAT; https:// www.fa.gov.tw/en/). The data were checked for consistencies and errors were removed. A weak seasonal variation, maximum in late spring and minimum in winter (e.g., Sassa et al. 2006), was removed to avoid possible artificial signal due to seasonal fishing. Yearly mean time series was constructed and long-term trend estimated (Bendat and Piersol 1986) (Fig. 1c), showing rising FC trend significant at the $99.9 \%$ confidence level. The strong rising FC trend from 1983 to approximately 1990 can be attributed to improved fishing technology, but thereafter the (weak) rising trend is probably related to increasingly more favorable biophysical environments that may increase productivity (Fig. S1, in the supplemental material; Sun 1998). We use only the FC 
data from 1990 to 2011. We remove the trend to focus on the interannual FC variation and its relation with the biophysical changes. At the end we comment on the trend in conjunction with interdecadal changes of Kuroshio transport reported in the literature.

To understand the FC time series (Fig. 1d), we focus on the winter to early spring period JFM and use Chl-a data from satellite as a proxy for phytoplankton and food availability. Comparing with other seasons, we will show that winter is the only season with the ideal Goldilocks temperature range potentially most favorable for fish growth. Recruitment then depends primarily on food availability, and we will show that the interannual changes in Chl-a are significantly related to the Kuroshio's sideways fluctuations through physical processes.

\section{b. Physical and ocean color data}

Daily $1 / 4^{\circ} \times 1 / 4^{\circ}$ gridded sea surface height anomaly $\left(\mathrm{SSHA}=\eta_{\mathrm{AVI}}{ }^{\prime}\right)$ data from 1993 to 2015 were obtained from AVISO (https://www.aviso.altimetry.fr/en/data. $\mathrm{html})$. The data have been corrected for aliasing of tides, and seasonal climatology is removed. The corresponding geostrophic currents $\mathbf{u}_{g}{ }^{\prime}$ are computed. The global mean sea level (GMSL) trend since $1993 \mathrm{GMSL}_{\mathrm{t} 93} \approx 3 \mathrm{~mm} \mathrm{yr}^{-1}$ (IPCC; https://www.ipcc.ch/publications_and_data/ar4/ wg1/en/faq-5-1.html; Bindoff et al. 2007) is removed to give $\eta_{\mathrm{AVI}}{ }^{\prime}$. The correlation of $\eta_{\mathrm{AVI}}{ }^{\prime}$ with Johns et al.'s (2001) measured transport at the WOCE PCM1 array (WOCE International Project Office; see Fig. 1b) is maximum at the offshore side of the Kuroshio (Fig. 1b) (cf. Gawarkiewicz et al. 2011). Following Gawarkiewicz et al. (2011), we use the $\eta_{\mathrm{AVI}}{ }^{\prime}$ at the maximum correlation site to define a Kuroshio transport index (KTI).

We use tide gauge data to provide a consistency check of the connection between sea level and KTI, to extend the record to presatellite data, and to later discuss longer-term (interdecadal) trends. The KTI correlates well $(r=0.8)$ with sea level anomaly $\left(\eta_{\mathrm{ISH}}{ }^{\prime}\right)$ measured at the Ishigaki tide gauge station. The $\eta_{\text {ISH }}$ begins at 1975 , a GMSL $\mathrm{t}_{75} \approx 2.2 \mathrm{~mm} \mathrm{yr}^{-1}$ [the sea level trend averaged over all tide gauge stations in the western North Pacific with data at least since 1975 (Oey and Chou 2016)] is removed from $\eta_{\mathrm{ISH}}{ }^{\prime}$. The GMSL $\mathrm{G}_{\mathrm{t} 75}$ agrees well with the IPCC estimate (Bindoff et al. 2007). The linear regressions of Kuroshio transport $\mathrm{KT}\left(\mathrm{Sv} ; 1 \mathrm{~Sv} \equiv 10^{6} \mathrm{~m}^{3} \mathrm{~s}^{-1}\right)$ with $\eta_{\mathrm{AVI}}{ }^{\prime}$ and $\eta_{\mathrm{ISH}}{ }^{\prime}$ are as follows:

$$
\begin{aligned}
& \mathrm{KT}(\mathrm{Sv})=45 \times \eta_{\mathrm{AVI}^{\prime}}(\mathrm{m})+21 \quad\left(r^{2}=0.69, p=0.0003\right), \\
& \mathrm{KT}(\mathrm{Sv})=31 \times \eta_{\mathrm{ISH}^{\prime}}(\mathrm{m})+22 \quad\left(r^{2}=0.36, p=0.004\right)
\end{aligned}
$$

These regressions are assumed to be valid at eddy and interannual time scales.

Other data used include surface Chl-a from the Ocean Color Climate Change Initiative (1998-2015; $4 \mathrm{~km} \times 4 \mathrm{~km}$ grid; http://www.esa-oceancolour-cci.org/), SST from GHRSST (1982-2015; 1/4 $\times 1$ 1/4 $^{\circ}$; https://www.ghrsst.org/), and wind from CCMP.V2 (1982-2015; 1/4 $\times 1 / 4^{\circ}$; http:// www.remss.com/measurements/ccmp). Monthly climatology is removed to study interannual variation. Composites (i.e., arithmetic averages) of various quantities are calculated based on strong and weak Kuroshio transports, or based on off-slope and on-slope Kuroshio sideways fluctuations. ${ }^{1}$ Strong Kuroshio transport $\mathrm{KT}^{+}$ is defined as transport that is greater than mean +1 standard deviation (StD), and weak Kuroshio transport $\mathrm{KT}^{-}$is defined as transport that is less than mean - 1 StD, similarly for off-slope and on-slope Kuroshio sideways fluctuations (Wang and Oey 2014). The shortest common period from 1998 to 2015 was used for composites, but the results are nearly the same if the SST and wind were composited for the longer periods from 1982 to 2015. The significance of differences (e.g., strong transport minus weak transport) is determined with a Student's $t$ test. All quoted correlations are above the $95 \%$ confidence level, calculated as $1-(1-0.95)^{2 /(F-1)}$, where $F=N / \tau_{N}$ is the degree of freedom, $N$ is length of time series, and $\tau_{N}$ is the dot product of the auto-covariances of the two time series.

\section{c. Numerical model}

To understand the relationship between transport, isotherm fluctuations, and cross-isobath flows, we use the results of an eddy-resolving $\left(0.1^{\circ} \times 0.1^{\circ}\right.$ horizontal resolution and 41 vertical levels) ocean model to calculate vorticity balance and composites based on strong and weak Kuroshio transports (Oey et al. 2014). The model, the Advanced Taiwan Ocean Prediction System (ATOP; http://mpipom.ihs.ncu.edu.tw/index.php; Oey et al. 2013), covers the entire North Pacific $\left(98^{\circ} \mathrm{E}-73^{\circ} \mathrm{W}\right.$ and $16^{\circ} \mathrm{S}-$ $70^{\circ} \mathrm{N}$ ); the model has been extensively validated (see Chang and Oey 2014a,b; Oey et al. 2014; Xu and Oey 2011, 2014, 2015; Huang and Oey 2015; Sun and Oey 2015; Sun et al. 2015; Lin and Oey 2016; Oey and Chou 2016; Wang and Oey 2016; and the ATOP website). The model was first run for 28 years (1988 to 2014) forced by the NCEP climatological surface fluxes and then was repeated for the same period driven by 6-hourly CCMP winds (http://www.remss.com/measurements/

\footnotetext{
${ }^{1}$ The two ways of calculating composites yield very similar results, since transport and sideways fluctuations are closely related (Wang and Oey 2014).
} 
ccmp); the latter 25 -yr model data from $1990-2014$ is then used for analysis.

\section{Results}

\section{a. KTI, PC1, and FC}

The Kuroshio transport index KTI and FC are positively correlated, with a maximum lagged correlation Corr(KTI, FC, 9) $=0.45$ when FC lags by 9 months (Fig. 1d). [Here, Corr(A, B, lag) = maximum lagged correlation coefficient with $p$ value of 0.05 or less between A and B with lags in months, positive (negative) if A leads (lags) B.] As mentioned above, the KTI is related to the sideways fluctuation index PC1 (Wang and Oey 2014), which is also shown in Fig. 1d. The KTI and PC1 have a maximum lagged correlation of 0.50 when KTI leads PC1 by 3 months. The PC1 and FC are also positively correlated, with a maximum lagged correlation of 0.67 when PC1 leads FC by 6 months. While correlation does not necessarily mean causal relation, which requires further analyses (below), the results of Fig. 1d tentatively suggest that increased Kuroshio transport may lead to off-slope shift of Kuroshio, which in turn may lead to increased fish catch.

\section{b. KTI and upwelling/downwelling isotherms through baroclinic response}

It is clear from Fig. 1d that the correlation between KTI and FC is weaker than between PC1 and FC. However, KTI is easily obtained from altimetry and/or tide gauge data (section 2) requiring no further (EOF) analysis. Kuroshio transport is also a preferred modeled diagnostic that can be directly and accurately calculated. We now establish the dynamical connection between Kuroshio transport and sideways fluctuation. We then use observations to relate KTI and PC1 to phytoplankton variability.

Increased Kuroshio transport can be due to current intensifying uniformly with depth with no change in the tilt of isotherms of the Kuroshio front. Measurements across the PCM1 array show that the increase has a strong baroclinic component, such that isotherms steepen and the current is intensified mostly near the surface (Johns et al. 2001). To understand the relationship between transport and isotherm fluctuations, we use the model results to composite the isotherm depth and along-Kuroshio volume flux $V$ at the PCM1 $x z$ section, where $x$ is cross-shore and $z$ is vertical. We composite for the period when the model Kuroshio transport anomaly from the mean exceeds $1 \mathrm{StD}\left(\mathrm{KT}^{+}\right)$, or strong-transport composite. We then repeat the composite calculation for the period when the Kuroshio transport anomaly from the mean is less than $-1 \mathrm{StD}$ $\left(\mathrm{KT}^{-}\right)$, or weak-transport composite. We plot their difference: $\delta \mathrm{KT}=\mathrm{KT}^{+}$minus $\mathrm{KT}^{-}$in Fig. 2a, which shows shallower isotherms inshore (blue shading) and deeper isotherms offshore (red shading) for stronger Kuroshio transport (white contours). This relation also applies to time-dependent Kuroshio transport and isotherm fluctuations, as indicated in Fig. 2b, which shows that the correlation between Kuroshio transport and isotherm depth is negative inshore and positive offshore. Finally, the temperature and volume flux $V$ composites for $\mathrm{KT}^{+}$and $\mathrm{KT}^{-}$(Figs. 2c,d) show cooler water near the coast and warmer water offshore for the strongtransport composite (Fig. 2c) and an opposite pattern for the weak-transport composite (Fig. 2d). In summary, isotherms rotate clockwise (anticlockwise) as Kuroshio transport increases (decreases), resulting in upwelling (downwelling) near the coast and deeper (shallower) isotherms farther offshore. The bulk of the transport change occurs in the upper layer (white contours), indicating strong vertical shear and baroclinic response through the thermal-wind balance (Pedlosky 1979):

$$
f \mathbf{k} \cdot \nabla \mathbf{u}+(\nabla \rho \times \nabla p) / \rho^{2} \approx 0,
$$

where $f$ is the Coriolis parameter, $\mathbf{k}$ is the vertical $(z)$ unit vector, $\mathbf{u}$ is the horizontal velocity, $\rho$ is density, and $p$ is pressure. The situation is schematically illustrated in "I" in Fig. 3a for $\mathrm{KT}^{+}$. The upper-layer depth $h_{1}$ decreases (increases), and $\partial h_{1} / \partial t<(>) 0$, on the shoreward side as Kuroshio transport increases (decreases). The model's strong baroclinic response agrees with the analysis of Johns et al. (2001) using direct measurements.

\section{c. Observed Kuroshio transport, sideways fluctuations, and phytoplankton blooming}

Guided by the model results that transport fluctuations are related to upwelling and downwelling inshore of the Kuroshio, we next use observations to relate phytoplankton response to the physical environments associated with strong and weak Kuroshio transports. We use Chl-a as a proxy for phytoplankton and food availability, and since recruitment variability is determined by the fish's early survival during the winter to early spring breeding season, we composite from 1998 to 2015 the JFM SST, Chl-a, and $\mathbf{u}_{g}{ }^{\prime}$ for $\mathrm{KT}^{+}$and $\mathrm{KT}^{-}$ (Figs. 3b,c). The $\mathbf{u}_{g}{ }^{\prime}$ shows cyclonic (anticyclonic) eddying pattern over the shelf break, consistent with off-slope (on slope) Kuroshio path for $\mathrm{KT}^{+}\left(\mathrm{KT}^{-}\right)$ (Wang and Oey 2014); the current is poleward (equatorward) along the Kuroshio consistent with a strengthened (weakened) flow in the surface layer when transport increases (decreases). The SST in the FC area 

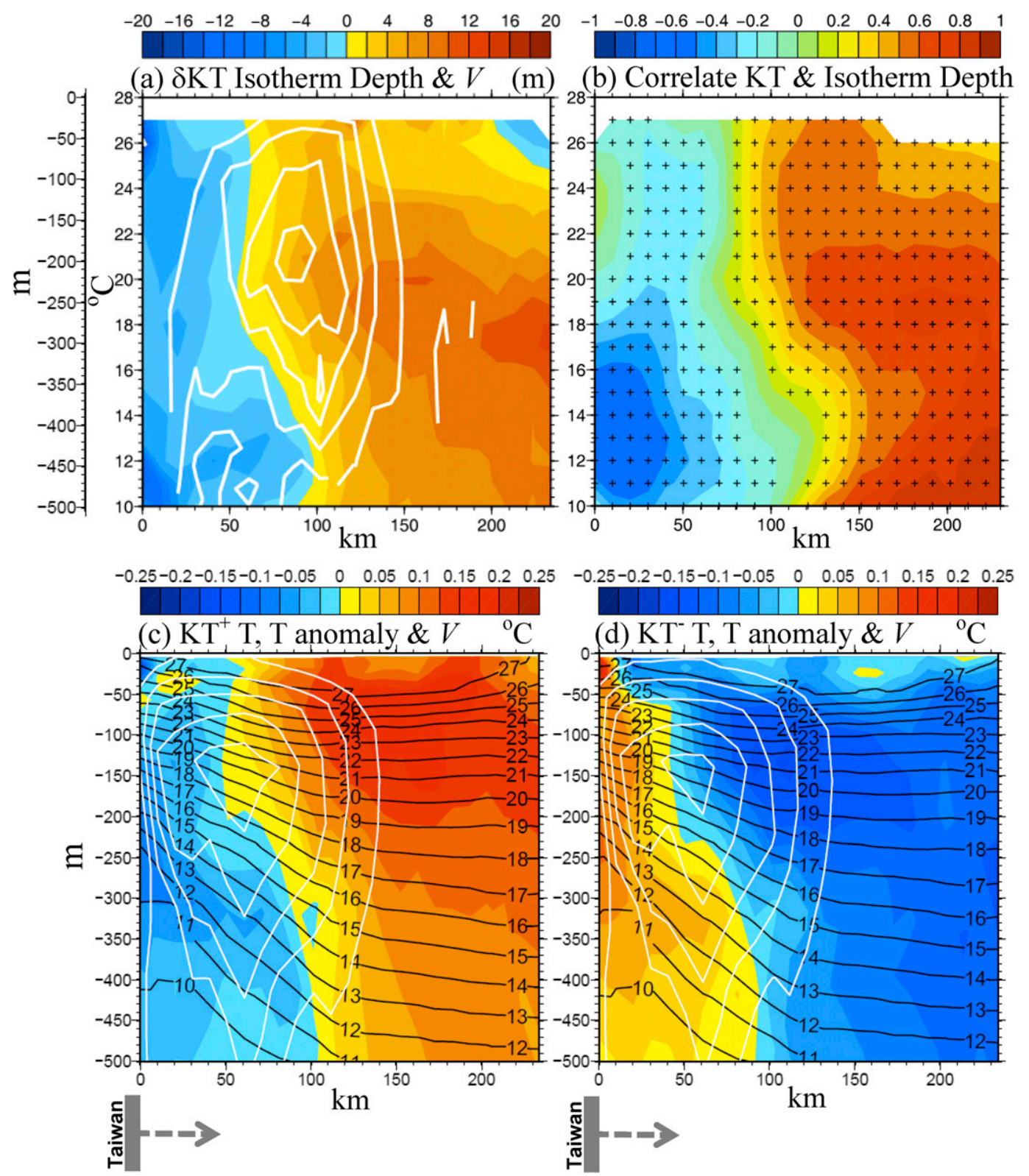

FIG. 2. (a) Difference of isotherm depths (shading; $\mathrm{m}$ ) and difference in volume fluxes (white contours $=0.01$, $0.02, \ldots, 0.05 \mathrm{~Sv}=v \Delta x \Delta z ; v=$ velocity along Kuroshio; $\Delta x$ and $\Delta z=$ cross-shore and vertical grid spacing) composited for model Kuroshio transport $>$ mean $+1 \mathrm{StD}, \mathrm{KT}^{+}$, and model Kuroshio transport $<$mean $-1 \mathrm{StD}$, $\mathrm{KT}^{-}$, the former minus the latter, plotted as a function of offshore distance $x$ from coast east of Taiwan at PCM1 (abscissa; km) (see Fig. 2a) and temperature (ordinate from $10^{\circ}$ to $28^{\circ} \mathrm{C}$, approximately from $z=-500 \mathrm{~m}$ to $z=0$; the $z$ scale on left). (b) Correlation coefficient between model Kuroshio transport and depth of isotherm; region where the correlation is significant at the $95 \%$ confidence level (i.e., $p$ value $\leq 0.05$ ) is stippled. (c),(d) Composites of model temperature (black contours; ${ }^{\circ} \mathrm{C}$ ), volume flux (white contours; $0.1,0.2, \ldots, 0.5 \mathrm{~Sv}$ ) and temperature anomalies (shading; ${ }^{\circ} \mathrm{C}$ ) at $\mathrm{PCM}$, for (c) $\mathrm{KT}^{+}$and (d) $\mathrm{KT}^{-}$, as a function of $x$ and depth below the surface (ordinate $z ; \mathrm{m})$. Seasonal climatology and long-term trends have been removed from time series.

falls within the Goldilocks range of $18^{\circ}-23^{\circ} \mathrm{C}$, ideal for breeding in agreement with previous in situ measurements (Sassa and Tsukamoto 2010; Sassa et al. 2014). We compare JFM and other seasons' composites: April-June
(AMJ), July-September (JAS), and October-December (OND) (Figs. 4a-d). In the FC area, it is clear that only in JFM is the temperature favorable for the mackerel to breed, while in other seasons the water is too warm, 
(a)
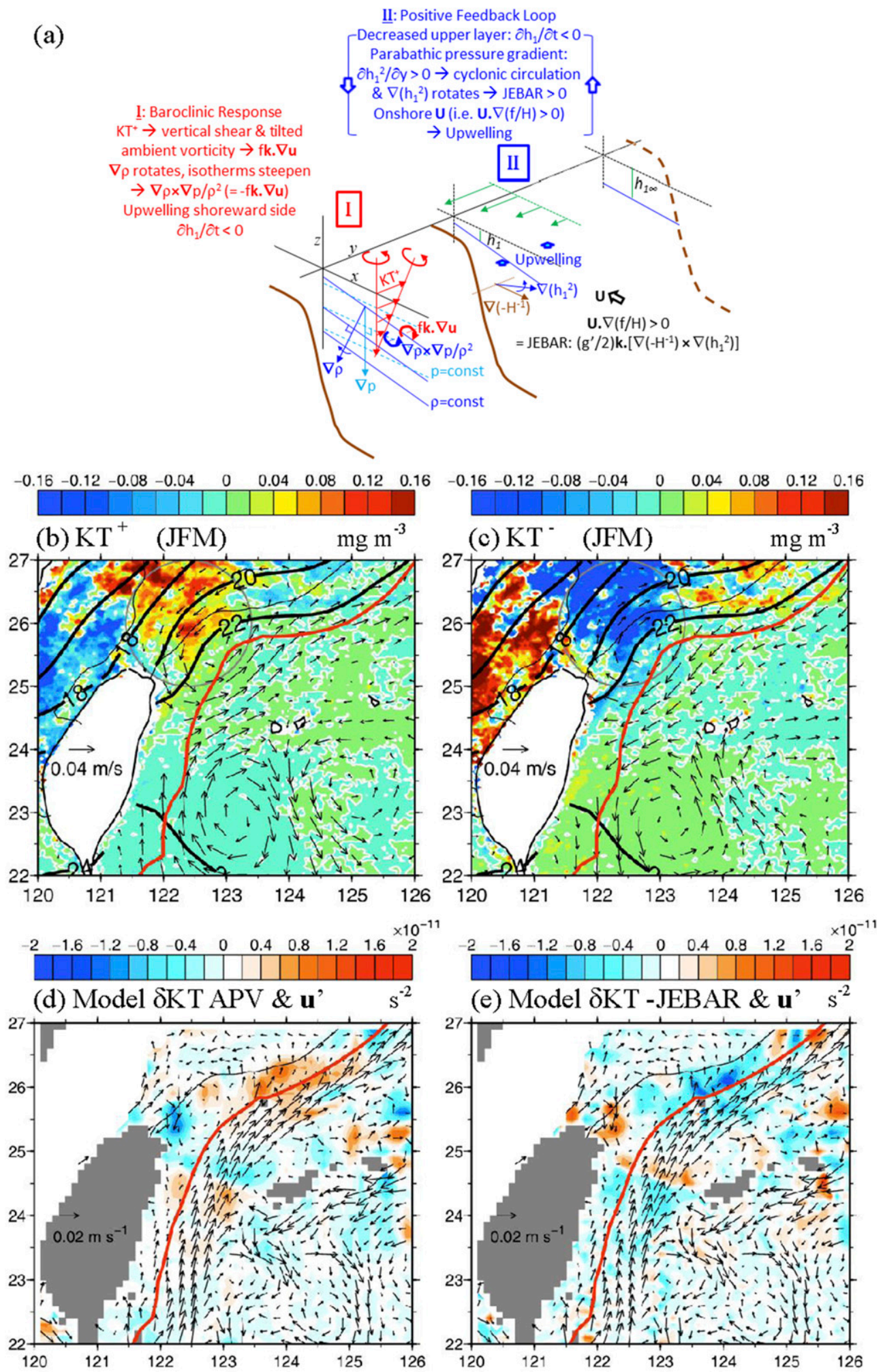

FIG. 3. (a) Schematic of (I) baroclinic response leading to upwelling and thinning of $h_{1}$ due to $\mathrm{KT}^{+}$and (II) development of JEBAR, on-shelf $\mathbf{U}$, and cyclonic circulation over the slope. (b), (c) Chl-a (shading with zero white contour), SST (black contours; ${ }^{\circ} \mathrm{C}$ ), and AVISO $\mathbf{u}_{g}{ }^{\prime}$ (vectors) composites for $\mathrm{KT}^{+}$and $\mathrm{KT}^{-}$for winter to early spring (JFM), with the gray circle indicating the $\mathrm{FC}$ area; (d),(e) $\mathrm{KT}^{+}$minus $\mathrm{KT}^{-}$composites of modeled APV and - JEBAR (shading) and 0-50-m averaged currents $\mathbf{u}^{\prime}$ (vectors). Red line shows (b),(c) observed and (d),(e) modeled mean Kuroshio paths. Thin black lines are 75- and 200-m isobaths. 

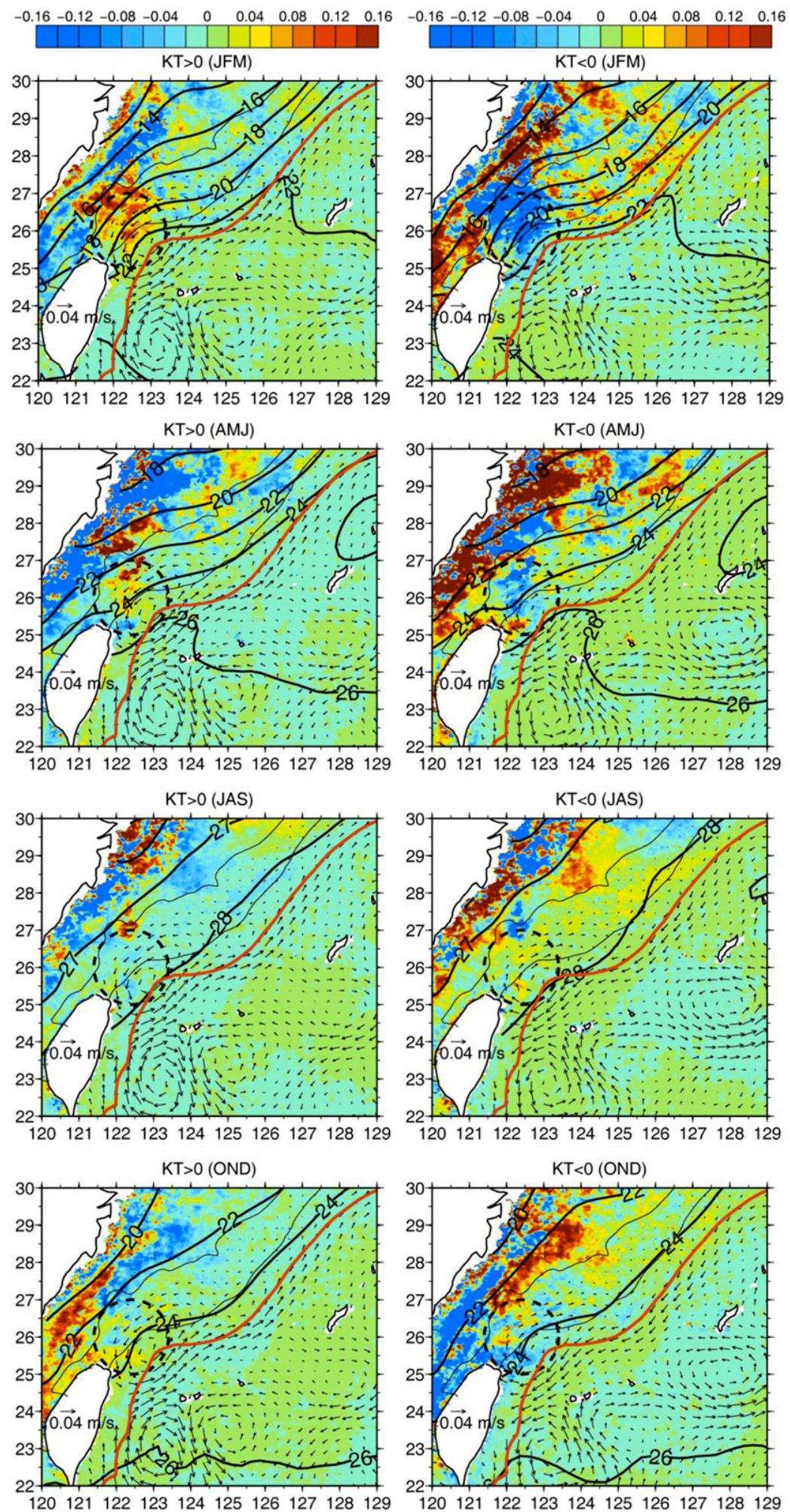

FIG. 4. A comparison of Chl-a (shading; $\pm 0.16 \mathrm{mg} \mathrm{m}^{-3}$ ) and SST (thick contours; $2^{\circ} \mathrm{C}$ interval except for JAS $=1^{\circ} \mathrm{C}$ ) composites for the four indicated seasons. Vectors are $\mathbf{u}_{g}^{\prime}$ (see Figs. 3b,c). Thin contours show the 75- and 200-m isobaths. Red is Kuroshio path and the circle NE of Taiwan is fish catch area. Note that the plot domain is larger than in Figs. 3b-e. 
especially in summer (JAS). On the other hand, at any season, differences between the two Kuroshio states are small, about $0.2^{\circ}-0.5^{\circ} \mathrm{C}$ (not plotted). Thus, while the JFM temperature is ideal for breeding, its interannual changes appear to be too weak compared to the background temperature to influence recruitment variability.

In the $\mathrm{FC}$ area, the Chl-a is enhanced (reduced) within the cyclonic (anticyclonic) eddy for $\mathrm{KT}^{+}\left(\mathrm{KT}^{-}\right)$ (Figs. 3b,c). ${ }^{2}$ Here, the anomaly $\approx \pm 0.16 \mathrm{mg} \mathrm{m}^{-3}$ exceeds the StD of 0.04 to $0.1 \mathrm{mg} \mathrm{m}^{-3}$ (the mean and StD are given in Fig. S2). Within the circled fish catch area in Figs. 3b,c, the negative anomaly for $\mathrm{KT}^{-}$is more widespread and has a larger amplitude (Fig. 3c; minimum $=-0.23 \mathrm{mg} \mathrm{m}^{-3}$ ) than the positive anomaly for $\mathrm{KT}^{+}$(Fig. 3b; maximum $=+0.17 \mathrm{mg} \mathrm{m}^{-3}$ ). Based on 25 years of near-surface drifter data, Wang and Oey (2016) have shown that the number of drifters intruding onto the southern ECS shelf across the shelf break is largest in fall and winter when the on-slope shift of the Kuroshio is strongest. Since the surface water of the Kuroshio has low nutrients (e.g., Chen 2008), the strong on-shelf intrusion would favor the depleted Chla response. The Chl-a difference $\left(\mathrm{KT}^{+}\right.$minus $\left.\mathrm{KT}^{-}\right)$ of $\approx 0.32 \mathrm{mg} \mathrm{m}^{-3}$ on a background mean of about $0.3 \mathrm{mg} \mathrm{m}^{-3}$ compares well with an interannual change of $0.1-0.3 \mathrm{mg} \mathrm{m}^{-3}$ in winter and early spring from field measurements (Sassa et al. 2014). In contrast, while the Chl-a patterns in other seasons generally have the same sign, the values are much weaker (Fig. 4). Indeed, the JFM values are so dominant that the total composite for all seasons (not shown) is also significant, albeit barely so. These results suggest the following chain of events that may give rise to interannual recruitment variability. From winter to early spring, the significantly enhanced (reduced) $\mathrm{Chl}$-a for $\mathrm{KT}^{+}\left(\mathrm{KT}^{-}\right)$lead to a larger (smaller) population of zooplankton and copepodites in the southern ECS, elevating (depressing) the food supply for mackerel larvae and juveniles whose growths are then increased (decreased) and their chance of survival into adults improved (diminished) (Chen et al. 2014; Sassa et al. 2014), which in turn may yield a larger (smaller) recruitment (Houde 1987; Sassa et al. 2014). The FC and KTI time series (Fig. 1d) seem to support such a biophysical relation. We found above that $\mathrm{FC}$ is positively correlated with KTI (Fig. 1d): Corr(KTI, FC, 9) $=0.45$, with FC lagging by about 9 months. Since Kuroshio

\footnotetext{
${ }^{2}$ The Chl-a anomalies near the coast in Figs. 3b,c and Fig. 4 are due to coastal sources and uncertainty and errors in satellite measurements near the coast (e.g., Blondeau-Patissier et al. 2014). We focus on waters deeper than the 75-m isobath where in JFM the temperature is within the Goldilocks range.
}

transport and sideways fluctuations (characterized by PC1) are related (Fig. 1d) (Wang and Oey 2014), FC is also significantly correlated with $\mathrm{PC} 1$ : $\operatorname{Corr}(\mathrm{PC} 1, \mathrm{FC}, 6)=0.67$ with FC lagging by about 6 months. Thus, during winter and early spring, not only is the temperature most ideal for the fish to breed, it is also the season when phytoplankton displays the most significant changes, which in turn may lead to interannual FC variations. But what are the driving physical processes?

\section{Mechanisms}

\section{a. Local scale}

We note from Figs. 3b,c that, in addition to the strong Chl-a variability in the FC area, there is also an elevated (reduced) level of Chl-a anomaly extending south along the eastern coast of Taiwan. The signal is weak but the sign is nonetheless consistent with enhanced (depressed) Chl-a caused by upwelling (downwelling) isotherms inshore of the Kuroshio as Kuroshio transport increases (decreases), described previously in Fig. 2. However, movements of isotherms and baroclinic response alone are insufficient to explain the eddying pattern, which requires further analyses. To understand why cyclonic (anticyclonic) recirculation is observed as Kuroshio transport increases (decreases), we composite terms in the $z$ component of the model depth-integrated vorticity equation (Oey et al. 2014) for $\mathrm{KT}^{+}$and $\mathrm{KT}^{-}$using 25-yr model data from 1990-2014. In the vicinity of the FC area, the main balance is between the advection of background potential vorticity (APV) and the joint effect of baroclinicity and relief (JEBAR) terms (cf. Wang and Oey 2016):

$$
\mathbf{U} \cdot \nabla(f / D) \approx J\left(\chi, D^{-1}\right), \text { i.e. } \mathrm{APV} \approx \mathrm{JEBAR} .
$$

Here, $\mathbf{U}$ is the horizontal transport vector (per unit length $), J\left(\chi, D^{-1}\right)=(\partial \chi / \partial x)\left(\partial D^{-1} / \partial y\right)-(\partial \chi / \partial y)\left(\partial D^{-1} / \partial x\right)$ is JEBAR (Huthnance 1984), $\chi=\int_{-H}^{\eta} z b d z^{\prime}, b=g \rho / \rho_{o}$, $\rho=$ density, $\rho_{o}=$ reference density, and $D$ is the total water depth. Differenced $\left(\mathrm{KT}^{+}\right.$composite minus $\mathrm{KT}^{-}$ composite) APV and -JEBAR composites are colorshaded in Figs. 3d,e, showing that the two terms nearly cancel and Eq. (2) is satisfied well. The differenced current (vertically averaged from surface to $50 \mathrm{~m}$ below the surface: $\mathbf{u}^{\prime}$ ) shows cross-isobath on-shelf flow near $\left(124^{\circ} \mathrm{E}, 26^{\circ} \mathrm{N}\right)$, where APV and JEBAR are positive, and off-shelf flow in a narrower coastal zone off the northeastern tip of Taiwan, where APV and JEBAR are negative, thus forming a cyclonic eddy pattern that straddles the FC area. The modeled cyclonic circulation pattern agrees well with the observed geostrophic current $\mathbf{u}_{g}{ }^{\prime}$-pattern inferred from AVISO, which as 
mentioned before shows cyclonic circulation for $\mathrm{KT}^{+}$ (Fig. 3b) and anticyclonic circulation for $\mathrm{KT}^{-}$(Fig. 3c) (i.e., their difference is cyclonic-see Fig. S3). The observed $\mathbf{u}_{g}^{\prime}$ shows on- and off-shelf diabathic flows at nearly exactly the locations described by the signs of the modeled APV and JEBAR. The discrepancy is over the shelf where the modeled $\mathbf{u}^{\prime}$ shows a northward outflow from the Taiwan Strait, but $\mathbf{u}_{g}^{\prime}$ does not; this may be expected since over the shallower shelf other terms in the vorticity balance are not negligible and Eq. (2) is not a good approximation (Oey et al. 2014).

The essential physics of the APV-JEBAR balance can be understood using a simpler two-layer planetary geostrophic model (Salmon 1992). Equation (2) becomes the following (Oey et al. 2010, appendix; also Wang and Oey 2014):

$$
\mathbf{U} \cdot \nabla(f / H)=\left(g^{\prime} / 2\right) \mathbf{k} \cdot\left[\nabla\left(-H^{-1}\right) \times \nabla\left(h_{1}^{2}\right)\right] .
$$

Here, $\mathbf{U}=\left(u_{1} h_{1}+u_{2} h_{2}, v_{1} h_{1}+v_{2} h_{2}\right)$ is the two-layer equivalent of the depth-integrated transport, $\mathbf{k}$ is the $z$-directed unit vector, subscripts 1 and 2 denote upper and lower layers, $u$ and $v$ are zonal $(x)$ and meridional $(y)$ velocities, $h$ is the layer depth, $H$ is the total water depth, and $g^{\prime}$ is the reduced gravity. The rhs is the JEBAR term written analogously to the baroclinic production term $(\nabla \rho \times \nabla p) / \rho^{2}$ in the thermal-wind relation (Pedlosky 1979). Thus the $-H^{-1}$ plays the role of density $\rho$ and $h_{1}^{2}$ is the pressure $p$, and the JEBAR on the rhs of Eq. (3) can be given a similar physical interpretation as the baroclinic production term (Wang and Oey 2016). Suppose the upper layer $h_{1}$ deepens northeastward along the isobath $H$. The $H$ is shallower on the left over the shelf $H=H_{\text {shallow }}$ and deeper on the right over the slope $H=H_{\text {deep }}$. The northeastward deepening of the upper layer $h_{1}$ sets up a southwestward, along-slope pressure gradient that pushes with the same force on the shallow water column over the shelf and the deep water column over the continental slope. Since the shallower water column is "less dense" than the deeper water column (i.e., $-H_{\text {shallow }}^{-1}<-H_{\text {deep }}^{-1}$ ), it is pushed more rapidly. The net result is therefore a cyclonic circulation over the sloping topography, and thus the rhs of Eq. (3) is positive. For low-Rossby number flow, this is balanced by an on-shelf flow $\mathbf{U} \cdot \nabla(f / H)>0$, according to Eq. (3). Additionally, a narrow off-shelf flow develops off the northern coast of Taiwan in order to satisfy the coastal boundary condition, closing the cyclone. Such a circulation pattern is seen in Figs. 3b,c (observation) and Fig. 3d or Fig. 3e (model).

Based on the above analyses of observations and model results, we describe in Fig. 3a the following mechanism of how the response to increased Kuroshio transport can result in an upwelling cyclone over the FC area. As Kuroshio transport near Taiwan increases, the upper-layer $h_{1}$ becomes shallower (Fig. 3a, I). Assuming that the effect of increased Kuroshio transport is confined mostly to the region northeast of Taiwan (see below), an increased along-slope pressure gradient force (per unit mass) is set up: $\left(g^{\prime} / 2\right) \partial h_{1}^{2} / \partial y>0$ (Fig. 3a, I), since farther downstream the upper layer remains undisturbed with depth $=h_{1 \infty}>h_{1}$. The vector $\nabla\left(h_{1}^{2}\right)$ before the increased Kuroshio transport is initially directed off shelf in geostrophic balance with the Coriolis force of the along-shelf current. It now rotates cyclonically as the transport increases, opening the angle it spans with the offshelf-directed vector $\nabla\left(-H^{-1}\right)$. A positive JEBAR is therefore produced, and, according to Eq. (3), it is balanced by an on-shelf transport $\mathbf{U} \cdot \nabla(f / H)>0$. The on-shelf $\mathbf{U}$ amplifies the upwelling over the sloping bottom, further reducing $\mathrm{h}_{1}$, strengthening $\partial h_{1}^{2} / \partial y$, and increasing the JEBAR angle as well as its magnitude, further reinforcing the on-shelf $\mathbf{U}$, and so on and so forth. The validity of the assumption that the effect of increased Kuroshio transport is confined mostly to the region northeast of Taiwan, so that JEBAR can develop, is provided by the model (Figs. 3d,e). To provide further quantitative evidence, we plot the correlation map of the Kuroshio transport index KTI with AVISO SSHA (Fig. S4a). The high correlation (say $r>0.4$ ) is mostly confined to east and northeast of Taiwan, and the correlation is low further downstream (e.g., at the "PN line", shown in Fig. 1b), suggesting that a change in transport at PCM1 does not readily trigger a covarying response further downstream. We also check the $\mathrm{PN}$-line transport estimated from hydrographic measurements and compare it with the regressed transport at PCM1 based on $\eta_{\text {ISH }}{ }^{\prime}$ (Fig. S4b); their correlations with and without the long-term trends removed are low and negative (about -0.3 ). These results support the assumption that changes in Kuroshio transport in the region northeast of Taiwan tend to be locally confined. There is also other evidence in the literature. In model simulations, Liu et al. (2014) found a strong JEBAR connection between Kuroshio transport and intrusion into the East China Sea. Soeyanto et al. (2014) suggested that Kuroshio transport along the slope of the East China Sea becomes uncorrelated owing to the presence of eddies. From observations, the structure of the mode-1 EOF of the Kuroshio path (Wang and Oey 2014) and paths of drifters (Wang and Oey 2016) show localized variability northeast of Taiwan.

\section{b. Effects of wind mixing}

The large Chl-a anomaly over the FC area changes sign to the northeast over the outer shelf and shelf break 
between the 75-m isobath and the Kuroshio (Fig. 4, JFM), forming a dipole. Although the Chl-a anomaly at the northeastern pole outside the FC area is much weaker and barely significant, the sign-change pattern requires an explanation. While the localized circulation discussed above may explain the Chl-a anomaly over the FC area, the JEBAR effect is weak further along the shelf (Guo et al. 2006; Oey et al. 2010; Wang and Oey 2014, 2016). Instead, since phytoplankton blooming depends on mixed layer depth (MLD) and level of turbulence (Sverdrup 1953; Huisman et al. 1999; Huang and Oey 2015; Lin and Oey 2016), we show in the appendix that differences in the spatial distribution of wind mixing power between the on-slope (weak transport) and offslope (strong transport) states of the Kuroshio can explain the Chl-a dipole pattern (see Fig. A1). Specifically, when the Kuroshio transport is weak and its path is on slope, we find that wind mixing power is strong over the FC area but weak to the north and northeast over the northern ECS shelf. The strong mixing deepens the MLD and enhances turbulence, and depresses phytoplankton blooming in the FC area, while the weak mixing to the northeast decreases MLD and turbulence, tending to enhance blooming.

\section{c. Remote influence}

In addition to local processes discussed above, Kuroshio variability is remotely driven. In this section, we attempt to relate remote influence to fish catch time series. Remote forcing can be characterized by a number of known climate indices relevant to the western North Pacific, for example, the El Niño-Southern Oscillation (ENSO) index. We examine how the fish catch time series are correlated to these interannually varying climate indices.

Chang and Oey (2011) found that westwardpropagating eddies from the subtropical countercurrent (Qiu 1999; Qiu and Chen 2010; Chang and Oey 2014b) modulate the interannual variation of Kuroshio transport east of Taiwan through the large-scale wind stress curl (WSC), which in turn may be characterized by a so-called Philippines-Taiwan Oscillation (PTO) index (Chang and Oey 2012). In years of positive PTO, the subtropical countercurrent front steepens leading to eddy abundance, and vice versa during negative PTO years. Other studies also indicate that nonlinear eddies play an important role (e.g., Soeyanto et al. 2014; Zhang et al. 2012). As FC is related to Kuroshio transport (Fig. 1d), we examine how it may be connected to WSC. We calculate their lagged correlation Corr(FC, WSC, lag) over the North Pacific Ocean (Fig. 5a). We find a lag of -6 months when the basin average of significant absolute correlation (at $95 \%$ confidence level) is a maximum. The Corr(FC, WSC, -6) pattern (Fig. 5a) shows a prominent area of significant positive correlation east of the Philippines, flanked to the north and south by areas of negative correlation. The pattern is remarkably similar to the PTO pattern of WSC (Chang and Oey 2012), which shows a prominent WSC-dipole east of Philippines and Taiwan, as shown in the map of Corr (PTO, WSC, 0) in Fig. 5b. The FC is in fact significantly correlated with PTO with a 5-month lag: $\operatorname{Corr}(\mathrm{FC}$, PTO, -5$)=0.47$. PTO is also closely linked to PC1, the mode-1 EOF of the Kuroshio path in the East China Sea (Wang and Oey 2014), and Corr(PC1, PTO, -4) $=0.73$. Therefore, unsurprisingly, the correlation map of PC1 with WSC, Corr(PC1, WSC, -6), also shows a dipole pattern east of the Philippines and Taiwan, although the northern pole is weaker (Fig. 5c), similar to the correlation map between FC and WSC (Fig. 5a). We check if FC is also related to other large-scale indices, such as the Pacific decadal oscillation (PDO) (Mantua et al. 1997), the El Niño-Southern Oscillation Niño-3.4 index, and the ENSO Modoki index (EMI). Only PDO shows a significant but weak correlation: $\operatorname{Corr}(\mathrm{FC}, \mathrm{PDO},-12)=0.22$. The map of Corr(PDO, WSC, 0) (Fig. 5d) shows that the WSC dipole is weaker and shifted eastward to the central Pacific, quite different from Figs. 5a-c. We conclude that the PTO pattern of the WSC dipole governs the interannual changes of Kuroshio transport in the subtropical North Pacific (Chang and Oey 2011, 2012, 2014b), which in turn dictates the local Kuroshio path (Wang and Oey 2014) and hence also the mackerel recruitment northeast of Taiwan. It is interesting that a recent study by Chang et al. (2016) also found a close link between PTO and the migration of Japanese eels in the western North Pacific.

\section{Summary and discussion}

We use observations to show that fish catch (FC) off northeastern Taiwan correlates interannually with the off-slope (more fish) and on-slope (less fish) fluctuations of the Kuroshio, characterized by the leading EOFmode principal component PC1 of the Kuroshio path: $r=0.67, p<0.001$, and FC lags by 6 months. The fish catch also correlates positively with Kuroshio transport. Locally, we show using a model that, through the combination of surface-intensified baroclinic response and balance between JEBAR and cross-isobath flow, an increased (decreased) Kuroshio transport triggers offshore (onshore) shift of the Kuroshio and upwelling cyclone (downwelling anticyclone), which are also observed. In both observation and model, the location of upwelling cyclone (downwelling anticyclone) coincides well with the FC area where significantly enhanced 

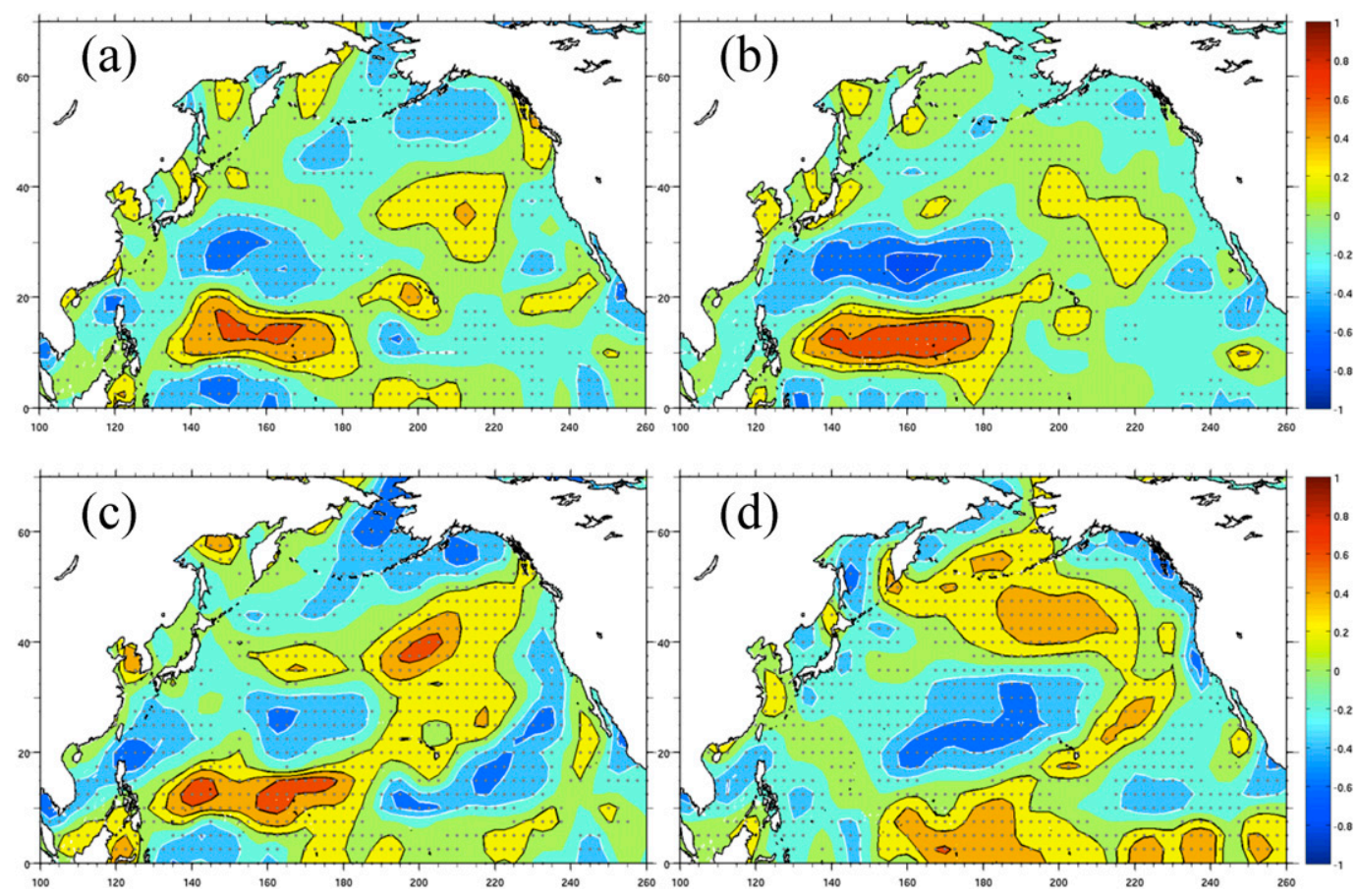

FIG. 5. Correlation maps between (a) FC and WSC with FC lagging by 6 months, that is, Corr(FC, WSC, -6); (b) $\operatorname{Corr}(\mathrm{PTO}, \mathrm{WSC}, 0)$; (c) Corr(PC1, WSC, -6), and (d) Corr(PDO, WSC, 0). Stipples indicate regions of significant correlation at the $95 \%$ confidence level. Black contours are $0.2,0.4$, and 0.6 , and white contours are -0.4 , -0.6 , and -0.8 . The WSC is from NCEP $2.5^{\circ} \times 2.5^{\circ}$ reanalysis. Time periods are 1990-2011 for FC, 1993-2014 for PC1, and 1950-2014 for PTO and PDO.

(depleted) phytoplankton concentration is observed during the breeding season from winter to early spring (JFM; Figs. 3b,c and Fig. 4). Moreover, we show that during that time the water temperature falls within the Goldilocks range that is most ideal for fish growth. The interannual changes in the Goldilocks SST range are weak, however, and therefore do not appear to have driven the observed FC variation. As recruitment of fish is largely determined during their early life stages (Houde 1987; Sassa and Tsukamoto 2010; Sassa et al. 2014, 2016), and the amount of zooplankton and copepodites that larvae and juveniles feed on is correlated with the phytoplankton concentration (Chen et al. 2014; Sassa et al. 2014), our findings suggest that faster- (slower-) growing larvae and juveniles in years with enhanced (depleted) phytoplankton would lead to more fish catch, which would explain the correlation between the Kuroshio transport and path and the FC time series. Remotely, we show that the interannual variation of FC is best related to the fluctuations of a WSC dipole (i.e., PTO) that straddles the subtropical countercurrent east of the Philippines and Taiwan (Chang and Oey 2012); this is because the PTO is strongly correlated with PC1. The correlation of FC with PDO or other climate indices is found to be poor. While we have thus established a plausible connection between circulation and phytoplankton variability, their relation with fish recruitment is much more complex, and a full understanding would require a comprehensive set of biophysical observations as well as ecosystem model experiments.

That a substantial portion of the $\mathrm{FC}$ variance $(45 \%)$ can be explained by a physical variable (PC1) in a western boundary current system influenced by a complex array of phenomena is, perhaps, somewhat surprising. The $45 \%$ is comparable to the percentages of biomass variance that can normally be explained by physical metrics used in a wind-driven coastal upwelling system (e.g., Cury et al. 2008; García-Reyes et al. 2014). That the FC lags the Kuroshio time series suggests the influence of the physical environment on the fish, which seems plausible. As PC1 has the largest amplitudes in summer and winter, the lag reflects the seasonal modulation of the Kuroshio; thus anomalous sideways shift of the Kuroshio in JFM is caused by the correspondingly strong shift in the previous summer (Wang and Oey 2014), which then influences the larvae and juveniles in the following winter/spring. As sideways fluctuations of the Kuroshio can be described using 
altimetry data, it may be possible to potentially provide a probability forecast of fish yield 6 months ahead.

Finally, we comment on the interdecadal trends of FC and Kuroshio transport. The regressed Kuroshio transport (after GMSL is removed) has a significant rising trend (e.g., Fig. S4b), at a rate of about 0.5 (based on $\eta_{\mathrm{AVI}}^{\prime}$; or 0.3 based on $\eta_{\mathrm{ISH}}{ }^{\prime}$ ) Sv decade ${ }^{-1}$. The geostrophic transport at the PN line also indicates an increasing trend (Zhang et al. 2012; Wei et al. 2013). England et al. (2014) have shown that over the past two decades during the so-called warming hiatus (e.g., L'Heureux et al. 2013), the Pacific Ocean shallow overturning cells have accelerated as a result of the pronounced strengthening of the trade winds. While Kuroshio transport is not the focus of their study, their model simulation shows a clear acceleration also of the tropical-subtropical gyre, including a strengthened western boundary current. Yamanaka et al. (2015) also found a similar gyre-strengthening for the period 1996-2006. These studies are consistent with our finding that the Kuroshio transport has strengthened at least since 1993. It is interesting that the FC too has a rising trend during the same period, raising the possibility that the same mechanism described herein for the interannual fluctuations may apply. Further research is required.

Acknowledgments. All data are publicly available and can be downloaded from links given in the text. We thank Y.-C. Lin for help with some of the figures. Authors were supported by Taiwan Ministry of Science and Technology Grant 106-2611-M-008-001, awarded to the National Central University.

\section{APPENDIX}

\section{The Chl-a Dipole and Wind Mixing}

Figure A1a plots the composite Chl-a difference between periods of on-slope $(\mathrm{PC} 1<0)$ and off-slope $(\mathrm{PC} 1>0)$ Kuroshio paths (note scale is double that used for Figs. 3b,c and Fig. 4), showing the Chl-a dipole comprising a southwestern pole over the FC area and a northeastern (weaker) pole of opposite sign over the outer shelf and shelf break between the $75-\mathrm{m}$ isobath and the Kuroshio. ${ }^{3}$ To assess the effects of mixing, we

\footnotetext{
${ }^{3}$ We focus on waters deeper than the $75-\mathrm{m}$ isobath within the Goldilocks temperature range, away from the coast; near the coast the accuracy of satellite-measured Chl-a is uncertain (BlondeauPatissier et al. 2014).
}

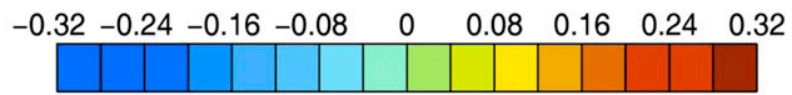

(a) Chl-a difference: on-slope minus off-slope Kuroshio
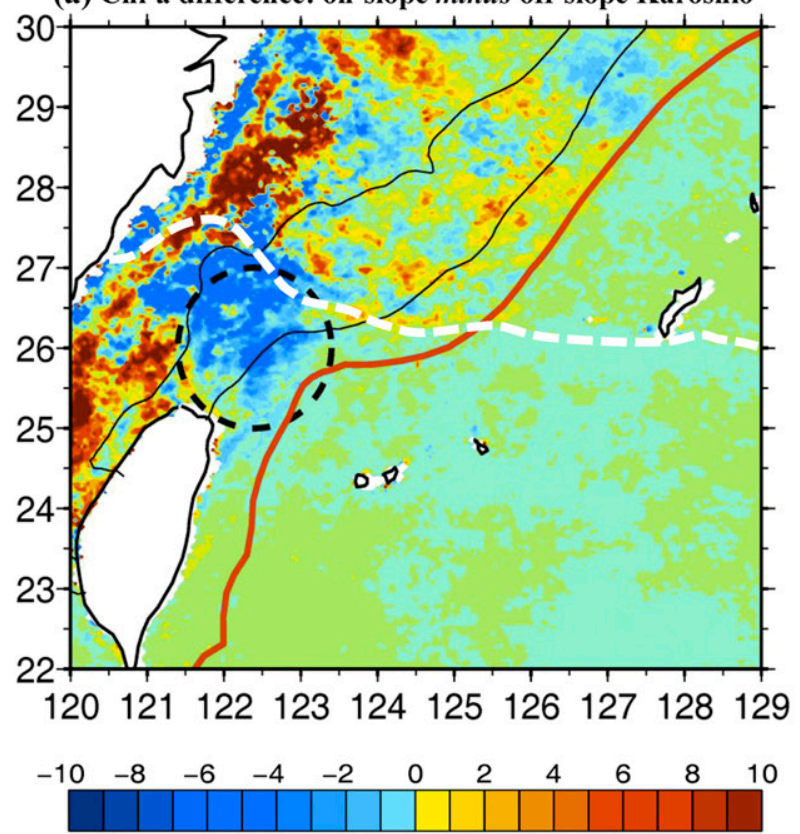

(b) $\mid$ Wind $\left.\right|^{3}$ difference: on-slope minus off-slope Kuroshio

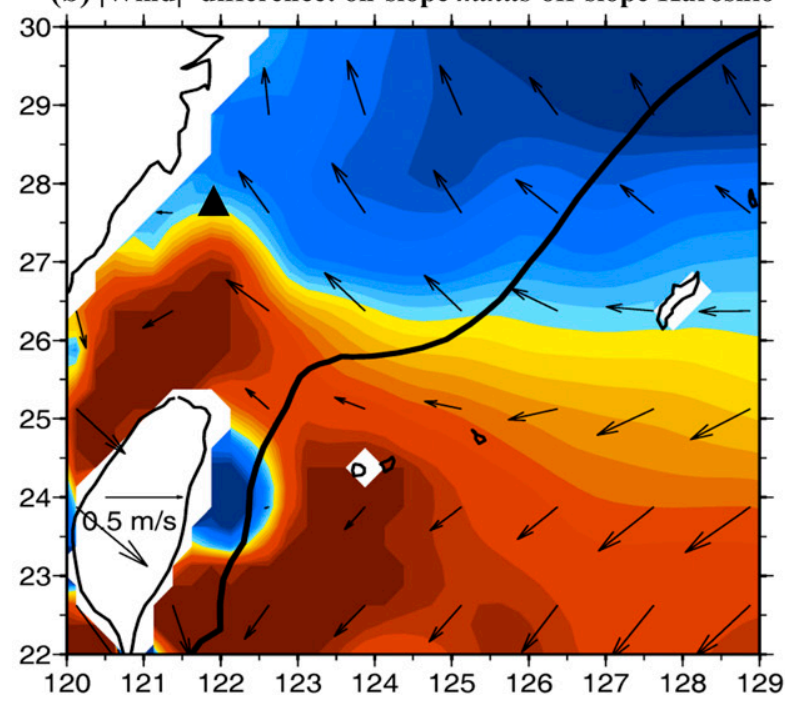

FIG. A1. Composite differences of (a) Chl-a (shading; $\mathrm{mg} \mathrm{m}^{-3}$ ) and (b) cubed JFM wind speed $\left(\times 10^{-3}\right)$ [shading; $\left.\left(\mathrm{m} \mathrm{s}^{-1}\right)^{3}\right]$ and wind (vectors; $\mathrm{m} \mathrm{s}^{-1}$ ) between periods of $\mathrm{PC1}(\mathrm{KTI})<0$ and $\mathrm{PC1}(\mathrm{KTI})>0$. In (a), white dashed line across central ECS shows the zero-contour line from (b) separating positive (south) and negative (north) wind power composite, black dashed circle indicates the FC area, red line shows the mean Kuroshio path, and thin black lines are the 75- and 200-m isobaths. In (b), the $\boldsymbol{\Delta}$ symbol marks where the onshore wind anomaly diverges north and south, and the black line is the mean Kuroshio path.

use $\mid$ wind $\left.\right|^{3}$ as a measure of the wind power that can vertically mix the surface layer of the ocean (Oey et al. 2006; Sun et al. 2015). We calculate wind and wind cubed 
composite differences (Fig. A1b) between the on-slope and off-slope phases of the Kuroshio (i.e. between weak and strong Kuroshio transport; Wang and Oey 2014). ${ }^{4}$ The anomalous wind is onshore across the ECS shelf and splits southward and northward around the $27.5^{\circ} \mathrm{N}$ near the coast (at the $\boldsymbol{\Delta}$ symbol in Fig. A1b). [Similar onshore wind anomaly was also noted in Wang and Oey (2014)]. To the south, the northeasterly monsoon wind is therefore strengthened, while to the north the monsoon wind is weakened. The resulting wind-power pattern is therefore also a dipole with its zero-contour line across the central ECS that separates the corresponding Chla composite into the southwestern pole of large negative anomaly and the northeastern pole of weak positive anomaly farther along the shelf (Fig. A1a). The different wind mixing power over the two poles, about 20$30 \mathrm{~W} \mathrm{~m}^{-2}$, results in a deeper (shallower) MLD over the southwestern (northeastern) pole. To estimate the MLD $\left(d_{\text {mix }}\right)$, consider shelf water of depth $H$ consisting of a mixed layer over a lower layer of depth $\left(H-d_{\text {mix }}\right)$ and slightly denser fluid $\delta \rho$. Then by equating the energy required to fully mix the two layers with the available wind power (Oey et al. 2006; Sun et al. 2015), one obtains the following:

$$
d_{\text {mix }}\left(H-d_{\text {mix }}\right) \approx 2 \gamma \tau P /(g \delta \rho),
$$

where $P=\rho_{\text {air }} C_{D}|W|^{3}$ is the wind power, $W$ is the wind speed, $C_{D}$ is the drag coefficient $\approx 1.3 \times 10^{-3}, \rho_{\text {air }}$ is the air density $\left(\approx 1.23 \mathrm{~kg} \mathrm{~m}^{-3}\right), g$ is the acceleration due to gravity, $\gamma$ is the mixing efficiency, and $\tau$ is the time scale over which the wind acts. Taking $\delta \rho=1 \mathrm{~kg} \mathrm{~m}^{-3}$, $g \approx 9.8 \mathrm{~m} \mathrm{~s}^{-2}, \tau \approx 1 \mathrm{day}, \gamma \approx 0.5 \%, H \approx 100 \mathrm{~m}$, and $P \approx 10 \mathrm{~W} \mathrm{~m}^{-2}$, we estimate that $d_{\mathrm{mix}} \approx 10-20 \mathrm{~m}$, and the difference in MLD between the two poles $2 d_{\text {mix }} \approx 20-40 \mathrm{~m}$. In simple biogeochemical models of phytoplankton blooming (e.g., Lin and Oey 2016), such a difference in MLD can result in different blooming. Thus the different MLD due to the wind power dipole may contribute to the weak anomaly seen over the northeastern pole (Fig. A1a).

Why is the anomalous wind onshore across the ECS shelf (Fig. A1b) when the Kuroshio is on slope? The problem involves coastal SST front and coupled air-sea dynamics based on ideas developed in Oey et al. (2014, 2015) and Wang and Oey $(2014,2016)$; see supplemental information. Briefly, wintertime on-shelf intrusion of warm water across the shelfbreak northeast of Taiwan

\footnotetext{
${ }^{4}$ Wind power is $\rho_{\text {air }} C_{D} \mid$ Wind speed $\left.\right|^{3}\left(\mathrm{~W} \mathrm{~m}^{-2}\right)$, where the drag coefficient $C_{D} \approx 1.3 \times 10^{-3}$ (Oey et al. 2006). Thus Fig. A1b is also wind power if the color scale is changed to $\pm 15 \mathrm{~W} \mathrm{~m}^{-2}$.
}

occurs more frequently during the on-slope than offslope phase of the Kuroshio (Wang and Oey 2014, 2016; Fig. S5). The warm water spreads along shelf as far north as the $29^{\circ}-30^{\circ} \mathrm{N}$ latitudes and onshore to the $50-\mathrm{m}$ isobath where it sharpens the SST gradient of the cold China Coastal Current (Oey et al. 2014; Wang and Oey 2016). Using a full-physics atmospheric general circulation model and an analytical model, Oey et al. (2015) then showed that a strengthened coastal SST front in winter forces a vertical recirculation cell in the atmospheric boundary layer above the front. By mass conservation the near-surface wind from the open ocean converges onshore toward the front and splits southward and northward near the coast (Fig. S6), in good agreement with the observed wind pattern in Fig. A1b. The Kuroshio and coastal SST front therefore modulate wind, probably in a coupled way, which in turn affects the ecosystem. This new perspective is interesting and deserves further research.

\section{REFERENCES}

Asami, T., 1974: Distribution of fish eggs and larvae in the southern Japan and its significance of source of the supply of fish stocks. Bull. Japan Soc. Fish. Oceanogr., 25, 176-192.

Barber, R. T., 2001: Upwelling ecosystems. Encyclopedia of Ocean Sciences, 2nd ed. Elsevier, 3128-3135.

Bendat, J. S., and A. G. Piersol, 1986: Random Data. Wiley, 566 pp.

Bindoff, N. L., and Coauthors, 2007: Observations: Oceanic climate change and sea level. Climate Change 2007: The Physical Science Basis, S. Solomon et al., Eds., Cambridge University Press, 385-432.

Blanchette, C. A., E. A. Wieters, B. R. Briotman, B. P. Kinlan, and D. R. Schiel, 2009: Trophic structure and diversity in rocky intertidal upwelling ecosystems: A comparison of community patterns across California, Chile, South Africa and New Zealand. Prog. Oceanogr., 83, 107-116, https://doi.org/ 10.1016/j.pocean.2009.07.038.

Blondeau-Patissier, D., J. Gower, A. Dekker, S. Phinn, and V. Brando, 2014: A review of ocean color remote sensing methods and statistical techniques for the detection, mapping and analysis of phytoplankton blooms in coastal and open oceans. Prog. Oceanogr., 123, 123-144, https://doi.org/10.1016/ j.pocean.2013.12.008.

Chang, Y.-L., and L.-Y. Oey, 2011: Interannual and seasonal variations of Kuroshio transport east of Taiwan inferred from 29 years of tide-gauge data. Geophys. Res. Lett., 38, L08603, https://doi.org/10.1029/2011GL047062.

_, and $\ldots$ 2014a: Analysis of STCC eddies using the Okubo-Weiss parameter on model and satellite data. Ocean Dyn., 64, 259-271, https://doi.org/10.1007/s10236-013-0680-7.

$\longrightarrow$, and - 2014b: Instability of the North Pacific subtropical countercurrent. J. Phys. Oceanogr., 44, 818-833, https://doi. org/10.1175/JPO-D-13-0162.1.

—, and —, 2016: The Philippines-Taiwan Oscillation: Monsoonlike interannual oscillation of the subtropical-tropical western North Pacific wind system and its impact on the ocean. J. Climate, 25, 1597-1618, https://doi.org/10.1175/ JCLI-D-11-00158.1. 
— C.-R. Wu, and L.-Y. Oey, 2009: Bimodal behavior of the seasonal upwelling off the northeastern coast of Taiwan. J. Geophys. Res., 114, C03027, https://doi.org/10.1029/ 2008JC005131.

—, L.-Y. Oey, C.-R. Wu, and F.-H. Lu, 2010: Why are there upwellings on the northern shelf of Taiwan under northeasterly winds? J. Phys. Oceanogr., 40, 1405-1417, https://doi.org/ 10.1175/2010JPO4348.1.

—, Y. Miyazawa, and M. Béguer-Pon, 2016: Simulating the oceanic migration of Japanese silver eels. PLOS ONE, 11, e0150187, https://doi.org/10.1371/journal.pone.0150187.

Chen, A., 2008: Distribution of nutrients in the East China Sea and the South China Sea connection. J. Oceanogr., 64, 737-751, https://doi.org/10.1007/s10872-008-0062-9.

Chen, C. T. A., and S. L. Wang, 2006: A salinity front in the southern East China Sea separating the Chinese coastal and Taiwan Strait waters from Kuroshio waters. Cont. Shelf Res., 26, 1636-1653, https://doi.org/10.1016/j.csr.2006.05.003.

Chen, W. Y., M. Lee, K. Lan, and G. Gong, 2014: Distributions and assemblages of larval fish in the East China Sea during the northeasterly and southwesterly monsoon seasons of 2008. Biogeosciences, 11, 547-561, https://doi.org/10.5194/bg-11-547-2014.

Cury, P. M., A. Bakun, R. J. M. Crawford, A. Jarre, R. A Quinones, L. J. Shannon, and H. M. Verheye, 2000: Small pelagics in upwelling systems: Patterns of interaction and structural changes in "wasp-waist" ecosystems. ICES J. Mar. Sci., 57, 603-618, https://doi.org/10.1006/jmsc.2000.0712.

- and Coauthors, 2008: Ecosystem oceanography for global change in fisheries. Trends Ecol. Evol., 23, 338-346, https://doi. org/10.1016/j.tree.2008.02.005.

Egerton, F. N., 2007: Understanding food chains and food webs, 1700-1970. Bull. Ecol. Soc. Amer., 88, 50-69, https://doi.org/ 10.1890/0012-9623(2007)88[50:UFCAFW]2.0.CO;2.

England, M., and Coauthors, 2014: Recent intensification of winddriven circulation in the Pacific and the ongoing warming hiatus. Nat. Climate Change, 4, 222-227, https://doi.org/10.1038/ nclimate2106.

Franks, P. J. S., 1992: Phytoplankton blooms at fronts: Patterns, scales, and physical forcing mechanisms. Rev. Aquat. Sci., 6, 121-137.

García-Reyes, M., J. Largier, and W. Sydeman, 2014: Synopticscale upwelling indices and predictions of phyto- and zooplankton populations. Prog. Oceanogr., 120, 177-188, https:// doi.org/10.1016/j.pocean.2013.08.004.

Gawarkiewicz, G., and Coauthors, 2011: Circulation and intrusions northeast of Taiwan: Chasing and predicting uncertainty in the cold dome. Oceanography, 24, 110-121, https://doi.org/ 10.5670/oceanog.2011.99.

Glenn, S., and C. Ebbesmeyer, 1994: The structure and propagation of a Gulf Stream frontal eddy along the North Carolina shelf break. J. Geophys. Res., 99, 5029-5046, https://doi.org/ 10.1029/93JC02786.

Guo, X. Y., Y. Miyazawa, and T. Yamagata, 2006: The Kuroshio onshore intrusion along the shelf break of the East China Sea: The origin of the Tsushima warm current. J. Phys. Oceanogr., 36, 2205-2231, https://doi.org/10.1175/JPO2976.1.

Hill, E., and Coauthors, 1998: Eastern ocean boundaries coastal segment. The Global Coastal Ocean: Regional Studies and Syntheses, A. Robinson and K. Brink, Eds., The Sea: Ideas and Observations on Progress in the Study of the Seas, Vol. 11, John Wiley and Sons, 29-68.

Houde, E. D., 1987: Fish early life dynamics and recruitment variability. Amer. Fish. Soc. Symp., 2, 17-29.
— 1989: Comparative growth, mortality, and energetics of marine fish larvae: Temperature and implied latitudinal effects. Fish Bull., 87, 471-495.

— , and C. E. Zastrow, 1993: Ecosystem- and taxon-specific dynamic and energetics properties of larval fish assemblages. Bull. Mar. Sci., 53, 290-335.

Huang, S.-M., and L.-Y. Oey, 2015: Right-side cooling and phytoplankton bloom in the wake of a tropical cyclone. J. Geophys. Res. Oceans, 120, 5735-5748, https://doi.org/ 10.1002/2015JC010896.

Huisman, J., P. van Oostveen, and F. J. Weissing, 1999: Critical depth and critical turbulence: Two different mechanisms for the development of phytoplankton blooms. Limnol. Oceanogr., 44, 1781-1787, https://doi.org/10.4319/ lo.1999.44.7.1781.

Huthnance, J. M., 1984: Slope currents and “JEBAR." J. Phys. Oceanogr., 14, 795-810, https://doi.org/10.1175/1520-0485 (1984)014<0795:SCA > 2.0.CO;2.

Huyer, A., 1983: Coastal upwelling in the California Current system. Prog. Oceanogr., 12, 259-284, https://doi.org/10.1016/ 0079-6611(83)90010-1.

Ichikawa, H., and R. C. Beardsley, 2002: The current system in the Yellow and East China Seas. J. Oceanogr., 58, 77-92, https:// doi.org/10.1023/A:1015876701363.

Isobe, A., 2004: Driving mechanism of band structure of mean current over the continental shelf. J. Phys. Oceanogr., 34, 1839-1855, https://doi.org/10.1175/1520-0485(2004)034<1839: DMOBSO $>2.0 . \mathrm{CO} ; 2$.

— 2008: Recent advances in ocean-circulation research on the Yellow Sea and East China Sea shelves. J. Oceanogr., 64, 569-584, https://doi.org/10.1007/s10872-008-0048-7.

Ito, T., A. Kaneko, H. Furukawa, N. Gohda, and W. Katerayama, 1995: Structure of the Kuroshio and its related upwelling on the East China Sea shelf slope. J. Oceanogr., 51, 267-278, https://doi.org/10.1007/BF02285165.

Johns, W. E., T. N. Lee, D. Zhang, and R. Zantopp, 2001: The Kuroshio east of Taiwan: Moored transport observations from the WOCE PCM-1 array. J. Phys. Oceanogr., 31, 10311053, https://doi.org/10.1175/1520-0485(2001)031<1031: TKEOTM $>2.0 . \mathrm{CO} ; 2$.

Kanaji, Y., Y. Watanabe, T. Kawamura, S. Xie, Y. Yamashita, C. Sassa, and Y. Tsukamoto, 2009: Multiple cohorts of juvenile jack mackerel Trachurus japonicas in waters along the Tsushima Warm Current. Fish. Res., 95, 139-145, https://doi.org/ 10.1016/j.fishres.2008.08.004.

Kessler, W. S., 2006: The circulation of the eastern tropical Pacific: A review. Prog. Oceanogr., 69, 181-217, https://doi.org/ 10.1016/j.pocean.2006.03.009.

Kim, H., S. Kimura, and T. Sugimoto, 2007: Transport of jack mackerel (Trachurus japonicus) larvae inferred from the numerical experiment in the East China Sea. Bull. Japan Soc. Fish. Oceanogr., 71, 9-17.

Lalli, C. M., and T. R. Parsons, 1997: Biological Oceanography: An Introduction. Elsevier, $320 \mathrm{pp}$.

Lee, T., and L. Atkinson, 1983: Low-frequency current and temperature variability from Gulf Stream frontal eddies and atmospheric forcing along the southeast U.S. outer continental shelf. J. Geophys. Res., 88, 4541-4567, https://doi.org/10.1029/ JC088iC08p04541.

L'Heureux, M., S. Lee, and B. Lyon, 2013: Recent multidecadal strengthening of the Walker circulation across the tropical Pacific. Nat. Climate Change, 3, 571-576, https://doi.org/ 10.1038/nclimate1840. 
Li, Y., X. Chen, C. Chen, J. Ge, R. Ji, R. Tian, P. Xue, and L. Xu, 2014a: Dispersal and survival of chub mackerel (Scomber Japonicus) larvae in the East China Sea. Ecol. Modell., 283, 70-84, https://doi.org/10.1016/j.ecolmodel.2014.03.016.

— fishing ground of chub mackerel (Scomber japonicus) in the East China Sea (in Chinese). Acta Ocean. Sin., 36, 67-74, https://doi.org/10.3969/j.issn.0253-4193.2014.06.009.

Lin, Y.-C., and L.-Y. Oey, 2016: Rainfall-enhanced blooming in typhoon wakes. Sci. Rep., 6, 31310, https://doi.org/10.1038/ srep31310.

Liu, C., F. Wang, X. Chen, and J.-S. von Storch, 2014: Interannual variability of the Kuroshio onshore intrusion along the East China Sea shelf break: Effect of the Kuroshio volume transport. J. Geophys. Res. Oceans, 119, 6190-6209, https://doi.org/ 10.1002/2013JC009653.

Liu, K. K., G. C. Gong, S. Lin, C.-Y. Yang, C. L. Wei, S. C. Pai, and C. K. Wu, 1992a: The year-round upwelling at the shelf break near the northern tip of Taiwan as evidenced by chemical hydrography. Terr. Atmos. Ocean. Sci., 3, 243-276, https://doi.org/ 10.3319/TAO.1992.3.3.243(KEEP).

$\longrightarrow,-$ C. Z. Shyu, S. C. Pai, C. L. Wei, and S. Y. Chao, 1992b: Response of Kuroshio upwelling to the onset of the northeast monsoon in the sea north of Taiwan: Observations and a numerical simulation. J. Geophys. Res., 97, 12 511-12 526, https:// doi.org/10.1029/92JC01179.

Lu, H.-J., C.-C. Chen, and J.-C. Cheng, 2013: Age and growth study of the jack mackerel (Trachurus japonicas) in the northeastern waters off Taiwan. J. Mar. Sci. Tech., 21 (Suppl.), $31-40$.

Mantua, N. J., S. R. Hare, Y. Zhang, J. M. Wallace, and R. C. Francis, 1997: A Pacific interdecadal climate oscillation with impacts on salmon production. Bull. Amer. Meteor. Soc., 78, 1069-1079, https://doi.org/10.1175/1520-0477(1997)078<1069: APICOW $>2.0 . \mathrm{CO} ; 2$

Oey, L.-Y., and S. Chou, 2016: Evidence of rising and poleward shift of storm surge in western North Pacific in recent decades. J. Geophys. Res. Oceans, 121, 5181-5192, https://doi.org/ 10.1002/2016JC011777.

, L. P. Atkinson, and J. O. Blanton, 1987: Shoreward intrusion of upper Gulf Stream water onto the U.S. southeastern continental shelf. J. Phys. Oceanogr., 17, 2318-2333, https://doi.org/10.1175/ 1520-0485(1987)017<2318:SIOUGS > 2.0.CO;2.

— T. Ezer, G. L. Mellor, and P. Chen, 1992: A model study of "bump" induced western boundary current variabilities. J. Mar. Syst., 3, 321-342, https://doi.org/10.1016/0924-7963 (92)90009-W.

— - — D.-P. Wang, S.-J. Fan, and X.-Q. Yin, 2006: Loop current warming by Hurricane Wilma. Geophys. Res. Lett., 33, L08613, https://doi.org/10.1029/2006GL025873.

_ - Y.-C. Hsin, and C.-R. Wu, 2010: Why does the Kuroshio northeast of Taiwan shift shelfward in winter? Ocean Dyn., $6 \mathbf{6}$, 413-426, https://doi.org/10.1007/s10236-009-0259-5.

_ - Y.-L. Chang, Y.-C. Lin, M.-C. Chang, F. Xu, and H.-F. Lu, 2013: ATOP-The Advanced Taiwan Ocean Prediction system based on the mpiPOM. Part 1: Model descriptions, analyses and results. Terr. Atmos. Ocean. Sci., 24, 137-158, https:// doi.org/10.3319/TAO.2012.09.12.01(Oc).

$-,-, \ldots,-$, S. Varlamov, and Y. Miyazawa, 2014: Cross flows in the Taiwan Strait in winter. J. Phys. Oceanogr., 44, 801-817, https://doi.org/10.1175/JPO-D-13-0128.1.

—, M.-C. Chang, S.-M. Huang, Y.-C. Lin, and M.-A. Lee, 2015: The influence of shelf-sea fronts on winter monsoon over
East China Sea. Climate Dyn., 45, 2047-2068, https://doi.org/ 10.1007/s00382-014-2455-3.

Pedlosky, J., 1979: Geophysical Fluid Dynamics. Springer, 626 pp. Pope, K. L., S. E. Lochmann, and M. K. Young, 2010: Methods for assessing fish populations. Nebraska Cooperative Fish and Wildlife Research Unit Staff Publ. 73, 27 pp., http:/ digitalcommons.unl.edu/ncfwrustaff/73.

Qiu, B., 1999: Seasonal eddy field modulation of the North Pacific Subtropical Countercurrent: TOPEX/Poseidon observations and theory. J. Phys. Oceanogr., 29, 2471-2486, https://doi.org/ 10.1175/1520-0485(1999)029<2471:SEFMOT $>2.0 . C O ; 2$

_ , and S. Chen, 2010: Interannual variability of the North Pacific subtropical countercurrent and its associated mesoscale eddy field. J. Phys. Oceanogr., 40, 213-225, https://doi.org/10.1175/ 2009JPO4285.1.

Salmon, R., 1992: A two-layer gulf stream over a continental slope. J. Mar. Res., 50, 341-365, https://doi.org/10.1357/ 002224092784797610.

Sanchez-Ramirez, M., and C. Flores-Coto, 1998: Growth and mortality of larval Atlantic bumper Chloroscombrus chrysurus (Pisces: Carangidae) in the southern Gulf of Mexico. Bull. Mar. Sci., 63, 295-303.

Sassa, C., and Y. Konishi, 2002: Distribution and transport of jack mackerel larvae and juveniles in the East China Sea. Kaiyo Mon., 31, 92-98.

_- and Y. Tsukamoto, 2010: Distribution and growth of Scomber japonicus and $S$. australasicus larvae in the southern East China Sea in response to oceanographic conditions. Mar. Ecol. Prog. Ser., 419, 185-199, https://doi.org/10.3354/meps08832.

_, Y. Konishi, and K. Mori, 2006: Distribution of jack mackerel (Trachurus japonicas) larvae and juveniles in the East China Sea, with special reference to the larval transport by the Kuroshio Current. Fish. Oceanogr., 15, 508-518, https:// doi.org/10.1111/j.1365-2419.2006.00417.x.

_ - Y. Tsukamoto, K. Nishiuchi, and Y. Konishi, 2008: Spawning ground and larval transport processes of jack mackerel Trachurus japonicus in the shelf-break region of the southern East China Sea. Cont. Shelf Res., 28, 2574-2583, https://doi.org/ 10.1016/j.csr.2008.08.002.

_- M. Takahashi, K. Nishiuchi, and Y. Tsukamoto, 2014: Distribution, growth and mortality of larval jack mackerel Trachurus japonicas in the southern East China Sea in relation to oceanographic conditions. J. Plankton Res., 36, 542-556, https://doi.org/10.1093/plankt/fbt134.

,,-- Y. Konishi, and Y. Tsukamoto, 2016: Interannual variations in distribution and abundance of Japanese jack mackerel Trachurus japonicus larvae in the East China Sea. ICES J. Mar. Sci., 73, 1170-1185, https://doi.org/10.1093/ icesjms/fsv269.

Shoji, J., T. Ohta, and M. Tanaka, 2006: Effects of river flow on larval growth and survival of Japanese seaperch Lateolabrax japonicus (Pisces) in the Chikugo River estuary, upper Ariake Bay. J. Fish Biol., 69, 1662-1674, https://doi.org/10.1111/ j.1095-8649.2006.01235.x.

Soeyanto, E., X. Guo, J. Ono, and Y. Miyazawa, 2014: Interannual variations of Kuroshio transport in the East China Sea and its relation to the Pacific decadal oscillation and mesoscale eddies. J. Geophys. Res. Oceans, 119, 3595-3616, https://doi. org/10.1002/2013JC009529.

Sun, C.-H., 1998: Optimal number of fishing vessels for Taiwan's offshore fisheries: A comparison of different fleet size reduction policies. Mar. Resour. Econ., 13, 275-288, https:// doi.org/10.1086/mre.13.4.42629242. 
Sun, J., and L.-Y. Oey, 2015: The influence of the ocean on Typhoon Nuri (2008). Mon. Wea. Rev., 143, 4493-4513, https:// doi.org/10.1175/MWR-D-15-0029.1.

,,-- R. Chang, F. Xu, and S.-M. Huang, 2015: Ocean response to typhoon Nuri (2008) in western Pacific and South China Sea. Ocean Dyn., 65, 735-749, https://doi.org/10.1007/ s10236-015-0823-0.

Sverdrup, H. U., 1953: On conditions for vernal blooming. ICES J. Mar. Sci., 18, 287-295, https://doi.org/10.1093/icesjms/ 18.3.287.

Takahashi, M., M. Yoneda, H. Kitano, A. Kawabata, and M. Saito, 2014: Growth of juvenile chub mackerel Scomber japonicus in the western North Pacific Ocean: With application and validation of otoloth daily increment formation. Fish. Sci., $\mathbf{8 0}$, 293-300, https://doi.org/10.1007/s12562-013-0698-2.

Tomczak, M., 1981: Coastal upwelling systems and eastern boundary currents. Geoforum, 12, 179-191, https://doi.org/ 10.1016/0016-7185(81)90019-1.

Wang, J., and L.-Y. Oey, 2014: Inter-annual and decadal fluctuations of the Kuroshio in East China Sea and connection with surface fluxes of momentum and heat. Geophys. Res. Lett., 41, 8538-8546, https://doi.org/10.1002/2014GL062118.

— , and - 2016: Seasonal exchanges of Kuroshio and shelf waters and their impacts on the shelf currents of the East China Sea. J. Phys. Oceanogr., 46, 1615-1632, https://doi.org/ 10.1175/JPO-D-15-0183.1.

Wei, Y., D. Huang, and X. H. Zhu, 2013: Interannual to decadal variability of the Kuroshio Current in the East China Sea from 1955 to 2010 as indicated by in-situ hydrographic data. J. Oceanogr., 69, 571-589, https://doi.org/10.1007/s10872-013-0193-5.

Wong, T. F. G., C.-C. Hung, and G.-C. Gong, 2004: Dissolved iodine species in the East China Sea-A complementary tracer for upwelling water on the shelf. Cont. Shelf Res., 24, 1465-1484, https://doi.org/10.1016/j.csr.2004.05.004.

Xu, F.-H., and L.-Y. Oey, 2011: The origin of along-shelf pressure gradient in the Middle Atlantic Bight. J. Phys. Oceanogr., 41, 1720-1740, https://doi.org/10.1175/2011JPO4589.1.
— , and - 2014: State analysis using the Local Ensemble Transform Kalman Filter (LETKF) and the three-layer circulation structure of the Luzon Strait and the South China Sea. Ocean Dyn., 64, 905-923, https://doi.org/10.1007/ s10236-014-0720-y.

— South China Sea. J. Phys. Oceanogr., 45, 1595-1609, https:// doi.org/10.1175/JPO-D-14-0193.1.

Yamanaka, G., H. Tsujino, H. Nakano, and M. Hirabara, 2015: Decadal variability of the Pacific subtropical cells and its relevance to the sea surface height in the western tropical Pacific during recent decades. J. Geophys. Res. Oceans, 120, 201-224, https://doi.org/10.1002/2014JC010190.

Yanagi, T., T. Shimizu, and H.-J. Lie, 1998: Detailed structure of the Kuroshio frontal eddy along the shelf edge of the East China Sea. Cont. Shelf Res., 18, 1039-1056, https://doi.org/ 10.1016/S0278-4343(98)80005-8.

Yasuda, T., R. Yukami, and S. Ohshimo, 2014: Fishing ground hotspots reveal long-term variation in chub mackerel Scomber japonicus habitat in the East China Sea. Mar. Ecol. Prog. Ser., 501, 239-250, https://doi.org/10.3354/meps10679.

Yoda, M., and Coauthors, 2012: Stock assessment and evaluation for jack mackerel Trachurus japonicus (fiscal year 2011) (in Japanese). Marine Fisheries Stock Assessment and Evaluation for Japanese Waters (Fiscal Year 2011/2012), Fisheries Agency and Fisheries Research Agency of Japan, 121-150.

Yukami, R., S. Ohshimo, M. Yoda, and Y. Hiyama, 2009: Estimation of the spawning grounds of chub mackerel Scomber japonicus and spotted mackerel Scomber australasicus in the East China Sea based on catch statistics and biometric data. Fish. Sci., 75, 167-174, https://doi.org/ 10.1007/s12562-008-0015-7.

Zhang, Q., Y. Hou, and T. Yan, 2012: Inter-annual and interdecadal variability of Kuroshio heat transport in the East China Sea. Int. J. Climatol., 32, 481-488, https://doi.org/ 10.1002/joc.2295. 